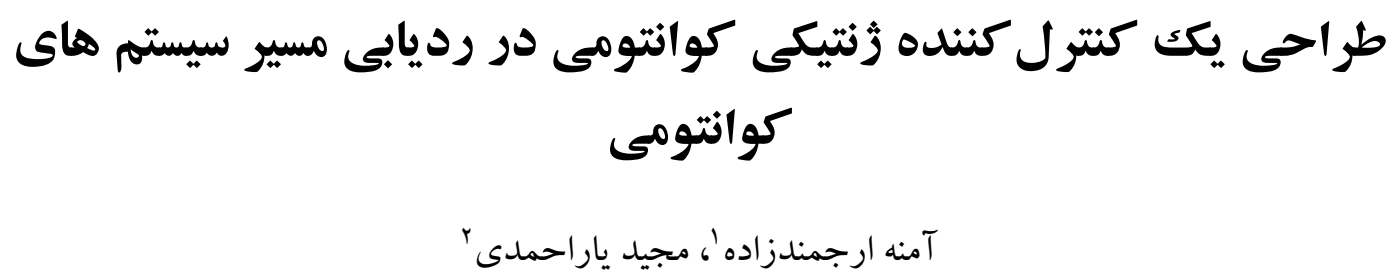

' فارغالتحصيل دكترى رياضى كاربردى، گروه رياضى و علوم كامبيوتر، دانشگاه لرستان،

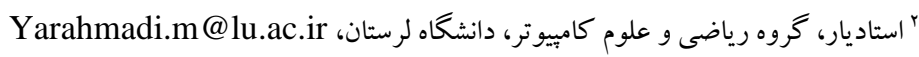

دريافت: ه/

$$
\begin{aligned}
& \text { جكيده: كنترل سيستمهاى كو انتومى مبتنى بر روشهاى كنترل ياد گير و هوش محاسباتى از موضوعات مورد توجه در حوزه مهندسى } \\
& \text { كنترل مىباشد. آنجه داراى اهميت است تضمين همخر ايى فر آيند كنترل موردنظر در عين وضوح و سادگى روش مىباشد. در اين مقاله يك } \\
& \text { فر آيند كنترل يادكير مبتنى بر يكك كنترل كننده زنتيكى كوانتومى به منظور رديابى مسير در سيستمهاى كوانتومى بسته ارائه شده است. } \\
& \text { كنترل كننده طراحى شده براى رديابى يك مسير متناظر يكك تابع متغير بازمان به كار گرفته شده است. براى اين منظور يكك مساله بهينهسازى } \\
& \text { مقيد با تابع هدف حداقل سازى انحر اف از مسير و محدوديت ناشى از ساختار تكرارى جواب معادله ديناميكى شرودينكر طر احى شده است. } \\
& \text { با توجه به نرخ بالاى همخر ائى در الكُوريتم زُنتيك كوانتومى، از الكوريتم زُنتيك كوانتومى براى حل مساله بهينه سازى استفاده شده است. بر } \\
& \text { اساس يكك اندازه گيرى تصادفى از نسل اول جمعيت حالات كوانتومى، الكوريتم زنتيكك حاصل بهترين كنترل كننده را براى رديابى مسير } \\
& \text { ارائه مىدهد. رديابى موثر و بهينه مسير با حداقل خطاى انحراف از مسير و حداقل نوسانات سيگنال كنترل از مزاياى روش ارائه شده است. } \\
& \text { دو مثال عددى براى نشان دادن عملكرد كنترل كننده طراحى و مزاياى آن ارائه شده است. نتايج شبيهازىهاى انجام شده نمايانكر صحت } \\
& \text { عملكرد روش ييشنهادى در كنترل سيستمهاى كوانتومى است. } \\
& \text { كلمات كليدى: الخوريتم زنتيك كوانتومى، رديابى مسير، سيستم كوانتومى، كنترل ياد گير }
\end{aligned}
$$

\title{
Designing a Quantum Genetic Controller for Tracking the Path of Quantum Systems
}

\section{Ameneh Arjmandzadeh, Majid Yarahmadi}

Abstract: Based on learning control methods and computational intelligence, control of quantum systems is an attractive field of study in control engineering. What is important is to establish control approach ensuring that the control process converges to achieve a given control objective and at the same time it is simple and clear. In this paper, a learning control method based on genetic quantum controller approach is presented. For tracking a time variant function trajectory, in a closed quantum system, the presented controller is used. For this purpose a constrained optimization problem, based on minimization of difference between a given trajectory and system states subject to an iteration relation of the dynamical solution be satisfied, is designed. According to high convergence rate in quantum genetic algorithm, a quantum genetic algorithm for solving the optimization problem is used. A stochastic measure for observation the initial population is used. Efficient an optimal tracking, with at least tracking errors and at least learned chattering are advantages of the presented method. A couple of examples for demonstrating the advantages are simulated. Simulation results reflect the good performance of the proposed method for controlling the quantum systems.

Keywords: Quantum Genetic Algorithm, Tracking Algorithm, Quantum Systems, Learning Control 
است كه در آن هر جرخه با يكك نمونهى جديد اجرا مىشود. خروجى هر

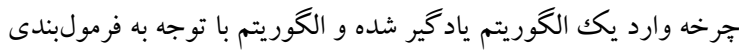
مناسب خود ورودى بعدى سيستم رابه نحوى بهتر تعيين مى كند. اين فرايند

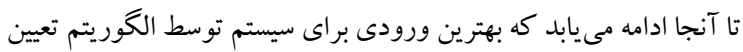

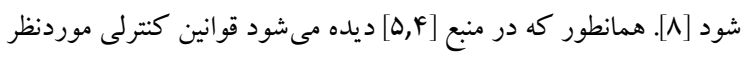

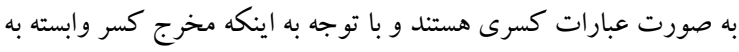

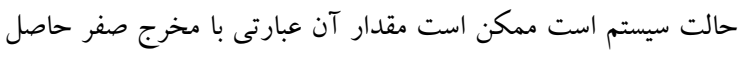

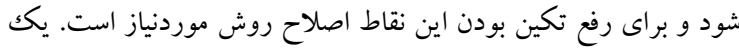

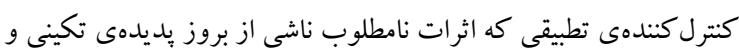

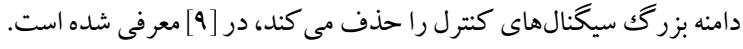

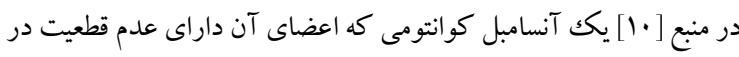

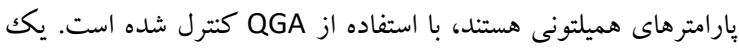

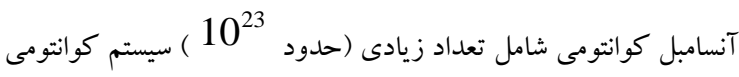
تنهاست.

در اين مقاله يك كنترل كننده زنتيكى كوانتومى در رديابى مسيره

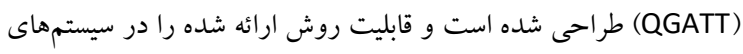

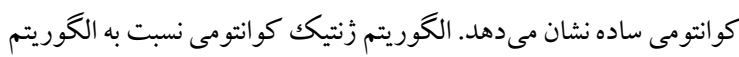

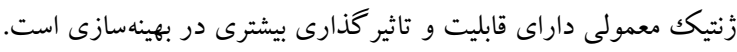

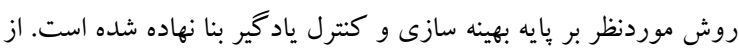
مزيتهاى روش گفته شده مواجه نشدن با نقاط تكين و عدم نياز به مشتق كيرى است.

در اين مقاله ابتدا توصيفى از مفاهيم مقدماتى محاسبات كوانتومى و

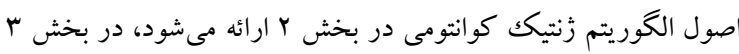

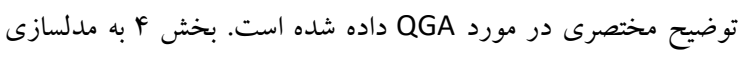
مساله كنترلى مى بردازد و در بخش ه دو مثال عددى حل مل شده و نتايج

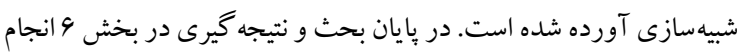

شده است.

\section{r - مفاهيم اوليه مكانيك كوانتومى}

هر سيستم كوانتومى در فضاى هيلبرت H قرار دارد كه اين فضا پايه

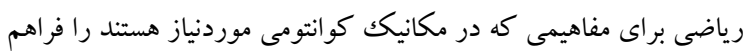

مى كند [11]. ك-1

بيت بايهاى ترين مفهوم محاسبات كلاسيكى است كه مىتواند يكى از دو

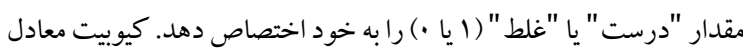
كوانتومى بيت است و يكك سيستم كوانتومى داراى دو حالت بايه

$$
|1\rangle=\left[\begin{array}{l}
0 \\
1
\end{array}\right],|0\rangle=\left[\begin{array}{l}
1 \\
0
\end{array}\right]
$$

1 - مقلمه

طى دو دهه اخير كنترل سيستمهاى كوانتومى محققين بسيارى را به

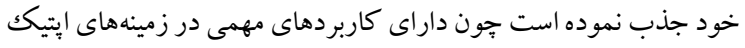

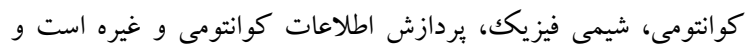

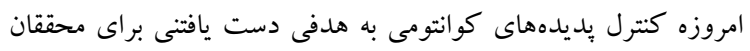

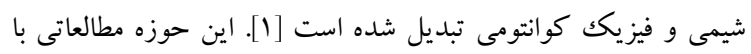

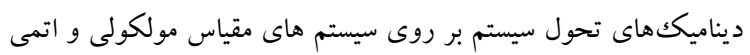

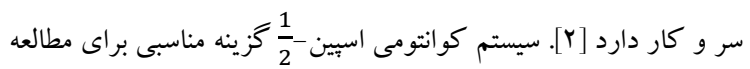

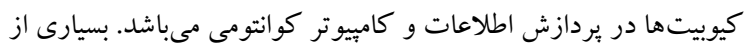

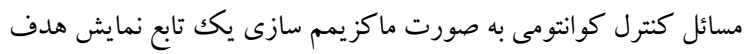

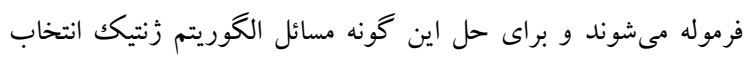

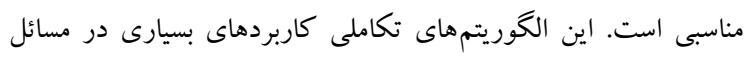

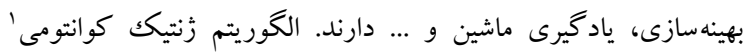

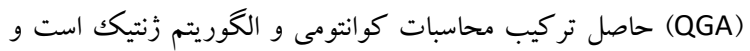

اولين بار توسط مور و نار ايانان در [r] معرفى شد.

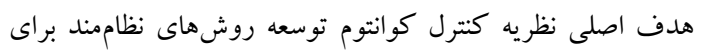

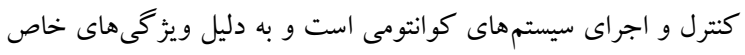
سيستمهاى ميكروسكويى كه در سيستمهاى كلاسيكى اتفاق نمىافتد، دستيابى به اين هدف داراى بيجيد گیىهايى است. يكى از مهمتر ين مسائل

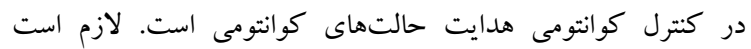

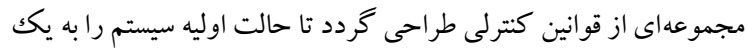
حالت هدف مطلوب ببر يم. در صورتى كه حالت هدف ساكن باشد، مساله

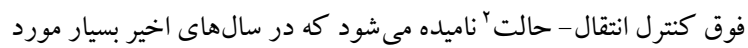

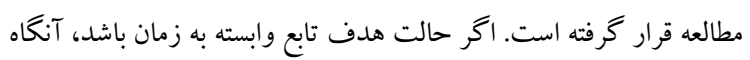

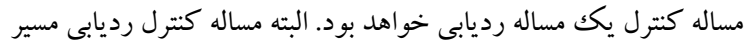

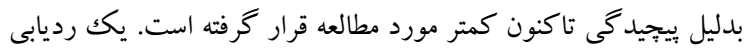

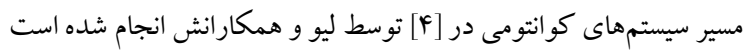

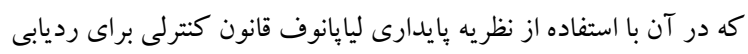

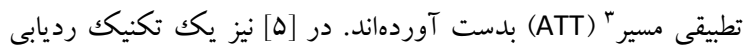
تطبيقى براى رفع مشكل تكينهايى كه در امتداد مسير با آن مواجه مى شوند

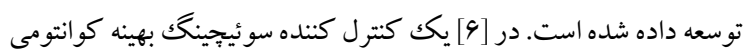
براى رديابى تطبيقى مسير " (SOAQTT) معرفى شده است كه تعداد نقاط تكينى را مديريت نموده و خطا و هزينه كنترل كه به صورت نرم كنترل است، كاهش داده است. در واقع معمولا هنگام مديريت يكك سيستم كوانتومى درهمتنيده،

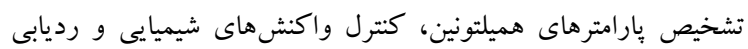

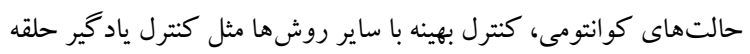
بسته مورد تر كيب واقع مى شود[V]. اين كنترل شامل عمليات حلقه بسته

\footnotetext{
${ }^{4}$ Switching Optimal Adaptive of Quantum Trajectory Tracking

${ }^{1}$ Quantum Genetic Algorithm

${ }^{2}$ State-Transfer

${ }^{5}$ Quantum Genetic Algorithm Trajectory Tracking

${ }^{3}$ Adaptive Trajectory Tracking
} 
زُنتيكى طبيعت هستند. در الكوريتم زُنتيك كوانتومى هر فرد از جمعيت به صورت يكك كروموزوم از حالات كوانتمى معرفى مى شود. كروموزومها

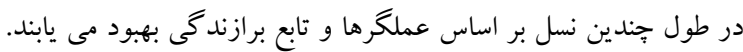

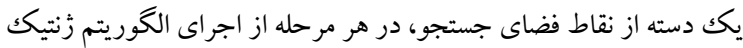

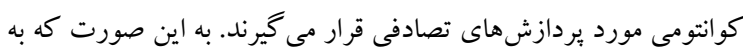

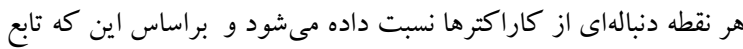

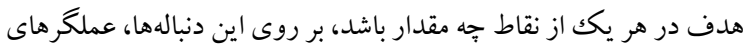
ززنتيكى كوانتومى اعمال مى شود به طورى كه هر كيوبيت از هر كروموزوم

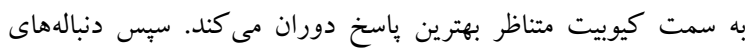

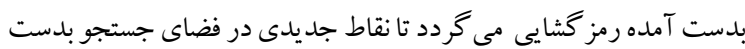

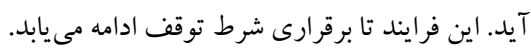

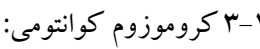
j-امين كروموزوم از p - امين نسل از جمعيت به صوروت

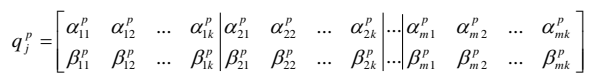

نوشته مىشود كه در آن k نمايانگر تعداد كيوبيتهاى هر زُن و

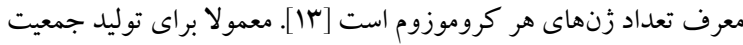
اوليه به هر حالت $)$ كه باعث مىشود هر حالت با احتمال برابر به حالتهاى بايه شكسته شود.

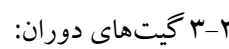
كيت هاى دوران به صورت دورن

$$
U(\theta)=\left[\begin{array}{cc}
\cos (\theta) & -\sin (\theta) \\
\sin (\theta) & \cos (\theta)
\end{array}\right]
$$

تعريف مىشوند كه در آن U عملگر دوران و $\theta$ زاويه دوران است. فرايند بروزرسانى يك كيوبيت

$$
\left[\begin{array}{l}
\alpha_{i}^{\prime} \\
\beta_{i}^{\prime}
\end{array}\right]=U\left(\Delta \theta_{i}\right)=\left[\begin{array}{cc}
\cos \left(\Delta \theta_{i}\right) & -\sin \left(\Delta \theta_{i}\right) \\
\sin \left(\Delta \theta_{i}\right) & \cos \left(\Delta \theta_{i}\right)
\end{array}\right]\left[\begin{array}{c}
\alpha_{i} \\
\beta_{i}
\end{array}\right]
$$

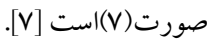

$\Delta \theta_{i} \quad$ به $\left[\begin{array}{l}\alpha_{i} \\ \beta_{i}\end{array}\right]$ به اندازه زوان يافتهى يك كيوبيت $\left[\begin{array}{c}\alpha_{i}^{\prime} \\ \beta_{i}^{\prime}\end{array}\right]$ وسيله گيت دوران U U است. در الكوريتم زُنتيك كوانتومى مقدار و علامت $\Delta \theta_{i}$ با استراتزى تنظيم مشخص مىشود و جرخش كيوبيتها

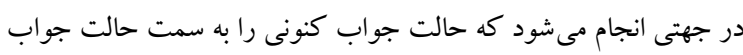
بهينه حركت دهد كه در جدول الرائه شده است [if] ، از كروموزوم بهينه جمعيت حاضر است؛ S $s\left(\alpha_{i}, \beta_{i}\right)$

زاويه جرخش است و معمولا حدود $0.01 \pi$ انتخاب مىشود [سا].

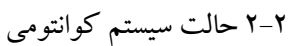
حالت سيستم كو انتومى اطلاعاتى است كه وضعيت سيستم را به طور كامل

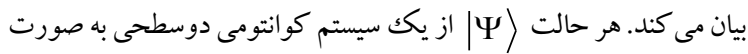
برهمنهشى از دو حالت بايه فوق به صورت (1) نوشته مى شود.

$$
|\Psi\rangle=\alpha|0\rangle+\beta|1\rangle
$$

$|\alpha|^{2}+|\beta|^{2}=1$ كه در آن م, $\alpha$ م اعداد مختلط هستند و در رابطه صدق مى كنند [IY]. حالت فيزيكى هر سيستم كو انتومى با يكك بردار نشان

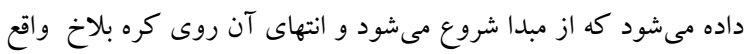

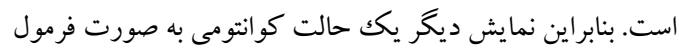

$$
|\Psi\rangle=\cos \left(\frac{\theta}{2}\right)|0\rangle+e^{i \varphi} \sin \left(\frac{\theta}{2}\right)|1\rangle
$$

است كه اعداد, $\theta, \quad$ مختصات كروى آن هستند. شكل ا حالت كو انتومى بر روى كره بلاخ را نشان مىدهد.

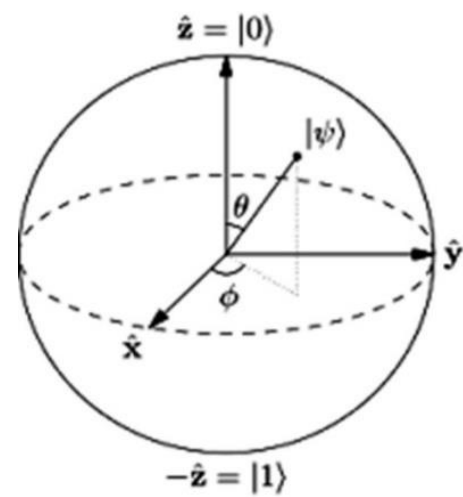

شكل ا: نمايش حالت خالص يكك سيستم كو انتومى روى كره بلاخ

فضاى هيلبرت سيستمهاى مركب از ضرب تانسورى فضاهاى سيستمهاى

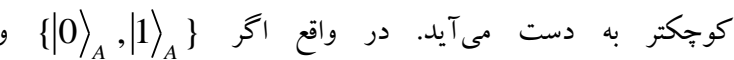
معادل دو $\mathrm{H}_{B}, \mathrm{H}_{A} \quad\left\{|0\rangle_{B},|1\rangle_{B}\right\}$

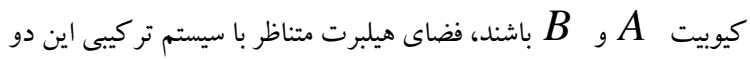
كيوبيت براير است با:

$$
\mathrm{H}_{A B}=\mathrm{H}_{A} \otimes \mathrm{H}_{B}
$$

$$
\text { كه با بايه متعامد يكهى ذيل مشخص مى شود. }
$$

$\left\{|0\rangle_{A} \otimes|0\rangle_{B},|0\rangle_{A} \otimes|1\rangle_{B},|1\rangle_{A} \otimes|0\rangle_{B},|1\rangle_{A} \otimes|1\rangle_{B}\right\}$

$$
=|00\rangle_{A B},|01\rangle_{A B},|10\rangle_{A B},|11\rangle_{A B}
$$

\section{r- التوريتم زنتيكى كوانتومى}

كيوبيتها و حالت برهمنهش كوانتومى، بايهاى ترين مفاهيم الكوريتم

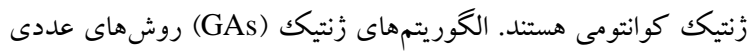

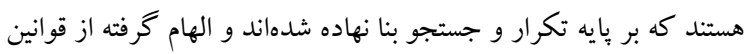




\begin{tabular}{|c|c|c|c|c|c|c|c|}
\hline \multicolumn{4}{|r|}{$s\left(\alpha_{i}, \beta_{i}\right)$} & \multirow{2}{*}{$\Delta \theta_{i}$} & \multirow{2}{*}{$f(x)>f($ best $)$} & \multirow{2}{*}{ best $_{i}$} & \multirow{2}{*}{$x_{i}$} \\
\hline$\beta_{i}=0$ & $\alpha_{i}=0$ & $\alpha_{i} \beta_{i}<0$ & $\alpha_{i} \beta_{i}>0$ & & & & \\
\hline 0 & 0 & 0 & 0 & 0 & غلط & 0 & 0 \\
\hline 0 & 0 & 0 & 0 & 0 & درست & 0 & 0 \\
\hline \pm 1 & 0 & -1 & +1 & $\Delta \theta_{i}$ & غلط & 1 & 0 \\
\hline 0 & \pm 1 & +1 & -1 & $\Delta \theta_{i}$ & | & 1 & 0 \\
\hline 0 & \pm 1 & +1 & -1 & $\Delta \theta_{i}$ & غلط & 0 & 1 \\
\hline \pm 1 & 0 & -1 & +1 & $\Delta \theta_{i}$ & | & 0 & 1 \\
\hline 0 & 0 & 0 & 0 & 0 & غلط & 1 & 1 \\
\hline 0 & 0 & 0 & 0 & 0 & درست & 1 & 1 \\
\hline
\end{tabular}

قرار دارد، مقدار جشمداشتى عملكَر اندازهيذير نشان داده مى شود [F] $Y(t)=\sum_{j} \gamma_{j}\left\langle\psi(t)\left|P_{j}\right| \psi(t)\right\rangle=\langle\psi(t)|P(t)| \psi(t)\rangle$ معادله (11) متغير كنترلشده است كه خروجى سيستم كنترل شده (1) نيز مىباشد. فرض كنيد $\rangle$ باشد. عملكر تصوير ويزه حالت اول $H_{0}$

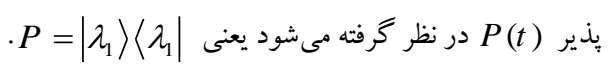

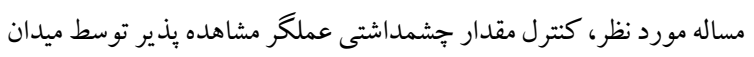
خارجى

$\operatorname{Min}\|s(t)-\langle\psi(t)|P(t)| \psi(t)\rangle\|$

s.t. $i \hbar \dot{\psi}(t)=H \psi(t)$

اكر معادله شرودينگر و عملكر تحول زمانى، فرمول

$$
|\psi(t)\rangle=e^{-i\left(H_{0}+\sum_{m=x, y} u_{m} H_{m}\right) \Delta t}|\psi(0)\rangle
$$

حاصل مىشود. لذا جون در عمل يافتن كنترل به صورت يكك تابع بيوسته وابسته به زمان مشكل است [1ه] با فرض ثابت بودن

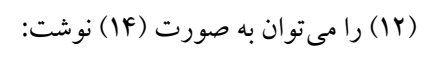
$\operatorname{Min}\left\|s(t)-\left\langle\psi(0)\left|e^{-i\left(H_{0}+\sum_{m=x, y} u_{m} H_{m}\right) \Delta t} P(t) e^{-i\left(H_{0}+\sum_{m=x, y}, u_{m} H_{m}\right) \Delta t}\right| \psi(0)\right\rangle\right\| \quad$ If $)$

اما در تابع هدف بِارامتر t هم وجود دارد براى حذف بِارامتر طول زيربازههاى كوجك t $t \in[t(k-1), t(k)], k=1,2, \ldots, Q$ زير بازه در نظر گرفت. بنابراين بازه [0,T] رابه

\section{ع- مدلسازى و روش حل}

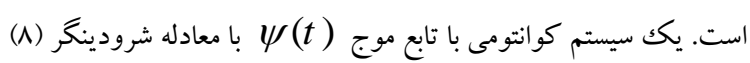
تعريف مىشود:

$$
i \hbar \psi(t)=H \psi(t)
$$

كه در آن $i=6.626068 * 10^{-34} j s$ عدد واحد موهومى و

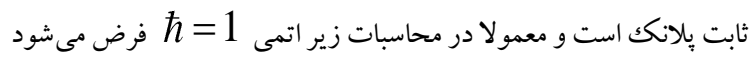
T [IY $H_{0}$ خارجى سيستم) مستقل از زمان فرض شدهاند. هدف كنترلى در اين مقاله هدايت مسير ديناميكى سيستم است به طوريكه مسير مطلوب (t) دنبال كند. يعنى من دين

$$
\langle\psi(t)|P(t)| \psi(t)\rangle=s(t)
$$

در واقع براى يكك سيستم كوانتومى بسته، كميتها يا مشاهدهيذيرها در

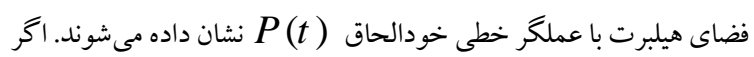
$P(t) \quad$ اندازه $P(t)$ خواهد بود. فرض كنيد حالت در لحظه اندازهيرى خ| باشد، احتمال بدست آوردن يكك مقدار $\gamma \in S$

$$
P_{\gamma}(\gamma \in S)=\left\langle\psi\left|P_{j}\right| \psi\right\rangle
$$

كه در آن $P_{j}$

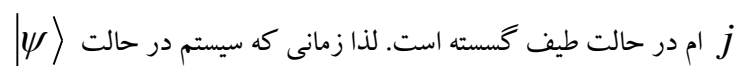


الكوريتمهاى رُنتيك روشهاى مبتنى بر تكرار هستند و اين تكرار تا

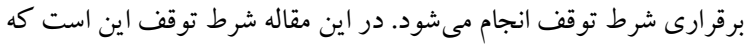

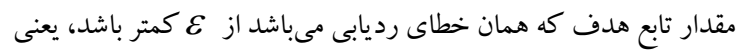

$$
\|e(t)\|=\|s(t)-Y(t)\|<\varepsilon
$$

\section{0- نتايج شبيه سازى}

در اين بخش دو مثال عددى به روش مذكور حل مى آنود تا تاثير كذارى

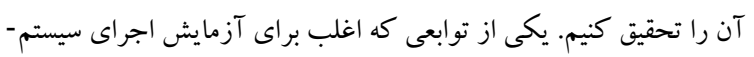

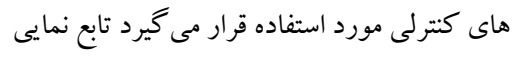

$$
s(t)=1-e^{-t / 2 \tau^{2}}, t \geq 0
$$

است كه در آن أمايانكر نرخ تغيير خروجى هدف است. هدف كنترلى

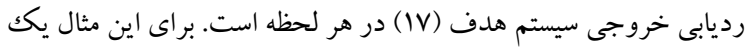
سيستم كوانتومى جهارسطحى در نظر بكيريد با هميلتونين كنترلى آزاد آنساد ، $E_{1}=0.4948$ آز كه در $H_{0}=\sum_{j=1}^{4} E_{j}|j\rangle\langle j|$ , $E_{4}=3.2434, E_{3}=2.3691 ، E_{2}=1.4529$

$$
H_{0}=\operatorname{diag}(0.4948,1.4529,2.3691,3.2434)
$$

براى اين سيستم، براى راحتى يك هميلتونين كتترلى كاملا متصل در نظر

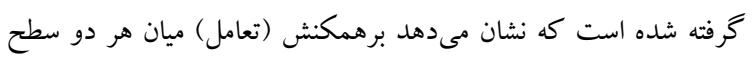
مجاز است. بنابر اين هميلتونين كنترلى به صورت

$$
H_{c}=\left[\begin{array}{llll}
0 & 1 & 1 & 1 \\
1 & 0 & 1 & 1 \\
1 & 1 & 0 & 1 \\
1 & 1 & 1 & 0
\end{array}\right]
$$

$$
\begin{aligned}
& \text { است و دو هميلتونين كنترلى به صورت زير انتخاب مىشوند: } \\
& H_{x}=\left[\begin{array}{llll}
0 & 1 & 1 & 0 \\
1 & 0 & 0 & 1 \\
0 & 1 & 1 & 0 \\
0 & 1 & 1 & 0
\end{array}\right], \quad H_{y}=\left[\begin{array}{llll}
0 & 1 & 0 & 1 \\
1 & 0 & 1 & 0 \\
0 & 1 & 0 & 1 \\
1 & 0 & 1 & 0
\end{array}\right] \\
& \text { هميلتونين كلى سيستم عبارت است از } \\
& H=H_{0}+u_{x}(t) H_{x}+u_{y}(t) H_{y} \\
& \text { مقادير ويزه ماتريس } \\
& \lambda_{4}=3.2434{ }_{6} \lambda_{3}=2.3691 \lambda_{2}=1.4529 \lambda_{1}=0.4948 \\
& \text { نشان داده مىشوند و بردار ويزّههاى متناظر عبارتند از: } \\
& \left|\lambda_{1}\right\rangle=[1,0,0,0]^{T}, \quad\left|\lambda_{2}\right\rangle=[0,1,0,0]^{T}, \\
& \left|\lambda_{3}\right\rangle=[0,0,1,0]^{T}\left|\lambda_{4}\right\rangle=[0,0,0,1]^{T}
\end{aligned}
$$

تقسيم مى كنيم و در هر زيربازه $t=\frac{T}{Q}$ مى-كنيم. همجنين عنوان نماينده هر زيربازه $|\psi(0)\rangle=|\psi(t(k-1))\rangle$ در نظر مى حالت اوليه سيستم خواهد بود. مساله مورد نظر به صورت : $\operatorname{Min} \| s\left(t_{k}\right)-\left\langle\psi\left(t_{k}\right)\left|P\left(t_{k}\right)\right| \psi\left(t_{k}\right)\right\rangle||$

$$
\text { s.t. }\left|\psi\left(t_{k}\right)\right\rangle=e^{-i\left(H_{0}+\sum_{m=x, y} u_{m}\left(t_{k}\right) H_{m}\right) \Delta t}\left|\psi\left(t_{k-1}\right)\right\rangle
$$

است كه در آن است. در مساله (ها) هدف يافتن كنترل

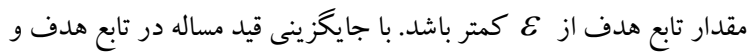
به كواب هاى بهينه ( QGA زيربازه يافت مىشود. الكوريتم فرايند موردنظر در زير آورده شده است.

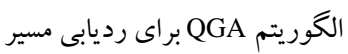
ا.قرار دهيد: 1 الغورتم Y.برار دهيد:

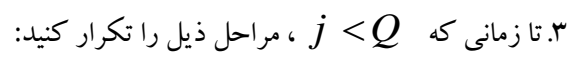
- كنترلهاى آغازين دلخواه - مسأله

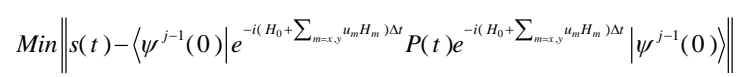
رابا QGA حل نموده و جواب بهينه

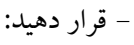

$$
\begin{aligned}
& \left|\psi^{j}(0)\right\rangle=e^{-i\left(H_{0}+\sum_{m=x, y} u_{m}^{* j} H_{m}\right) \Delta t}\left|\psi^{j-1}(0)\right\rangle \\
& j \leftarrow j+1 \\
& \text { F. جواب بهينه عبارت است از: } \\
& u_{m}^{*}=\left\{u_{m}^{* j}, j=1,2, \ldots, Q\right\}, m=x, y
\end{aligned}
$$

همجنين در شكل r دياكر ام فرايند روش مذكور نشان داده شده است. Main Problem

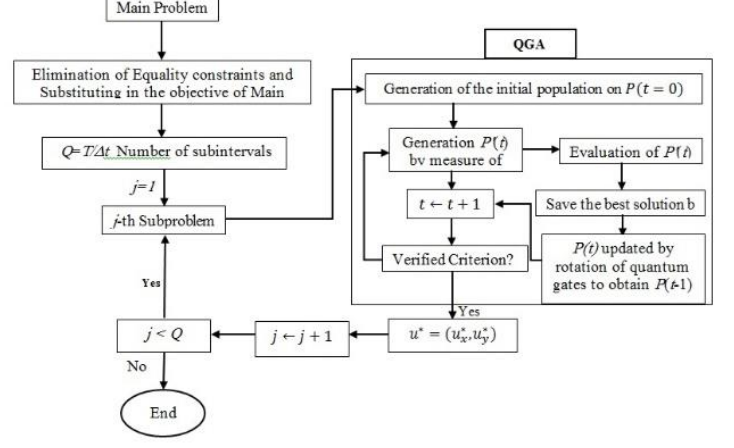

شكل r: نمايش حالت خالص يكك سيستم كو انتومى روى كره بلاخ 


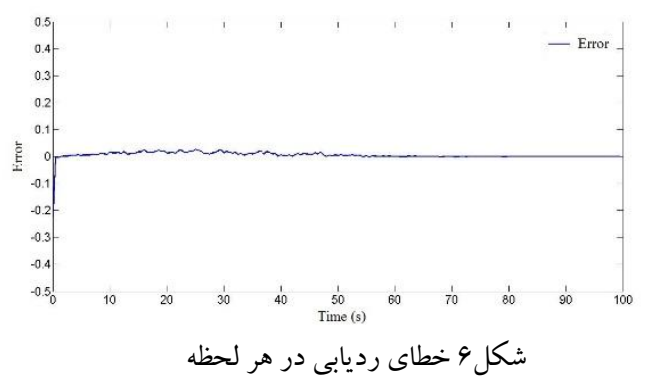

مثال فوق در منبع [\&] با استفاده از روش ليايانوف در رديابى تطبيقى مسير حل شده و دقت كنترل 0.99 حاصل شده است يعنى رديابى با خطاى دون 0.01 انجام شده است. مقايسه نتايج روش ارائه شده در اين مقاله با روش دوش

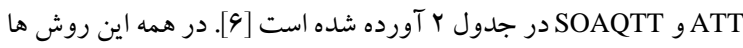
بعد از · ثانيه خطا به صفر ميل مى كند. خروجى سيستم در ATT مسير

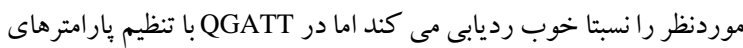

مساله مى توان با هر دقت مورد نظر رديابى مسير را انجام داد.

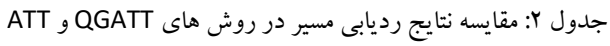

\begin{tabular}{|c|c|c|c|}
\hline QGATT & SOAQTT & ATT & شاخص عملكرد/ روش \\
\hline 0.02 & 0.0175 & 0.0182 & IAE \\
\hline 0 & 372 & 702 & تهلهاد نقاط تكينغ \\
\hline 5.2813 & 33.3815 & 39.7493 & $u$ \\
\hline 5.2245 & 18.7795 & 18.9577 & $u_{v}$ \\
\hline
\end{tabular}
شاخص خطاى كنترل به صورت IAE =

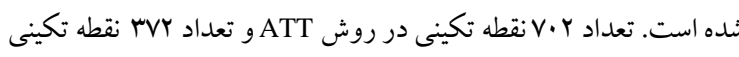

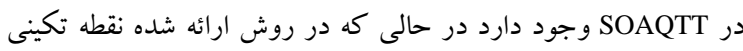

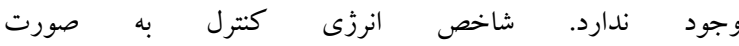
ن ز نرم كنترل كننده نيز نشان مى دهد كه روش AGATT داراى هزينه كنترل كمترى نسبت به بقيه روش هاست.

\section{7- نتيجه Fيرى}

در اين مقاله مبتنى بر رويكرد كنترل ياد گير و بهينهسازى يك كنترل كننده كو انتومى در رديابى مسير براى سيستمهاى كوانتومى بسته ارائه شده است.

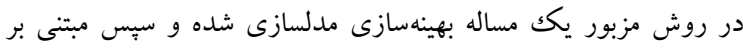

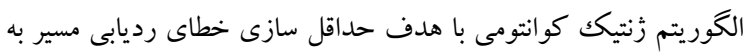

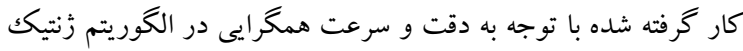

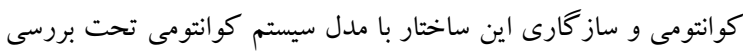

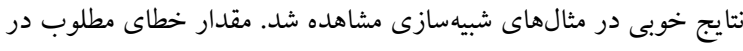

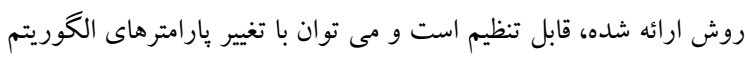
زُنتيكك و ساير بارامترهاى مساله، با هر دقت دلخواهى مسير را رديابى نمود.

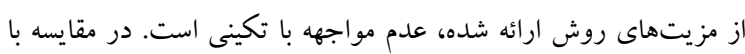

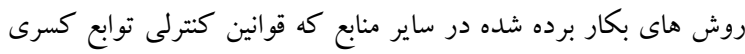

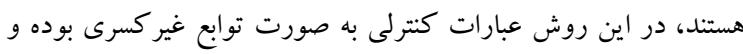

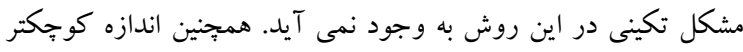

$$
p=\left|\lambda_{1}\right\rangle\left\langle\lambda_{1}\right|=\left[\begin{array}{llll}
1 & 0 & 0 & 0 \\
0 & 0 & 0 & 0 \\
0 & 0 & 0 & 0 \\
0 & 0 & 0 & 0
\end{array}\right]
$$

حالت اوليه براى سيستم كنترل شده (N) برهمنهش بردار ويزههاى

$$
\text { : به صورت زير است: }\left|\lambda_{i}\right\rangle \text {, } i=1,2,3,4
$$

$$
\left|\Psi_{0}\right\rangle=0.5\left|\lambda_{1}\right\rangle+0.5\left|\lambda_{2}\right\rangle+0.5\left|\lambda_{3}\right\rangle+0.5\left|\lambda_{4}\right\rangle
$$

مقدار ع عرابر 0.01 انتخاب شدهاستو 20 است. مسير در اسر بازه زمانى [0,100] رديابى مىشود كه به .... ز زير بازه با طول

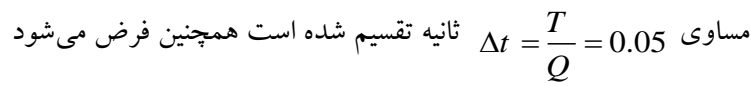
كه در هر قطعه زمانى مقادير كنترل ثابت است. تعداد جمعيت •ه و طول

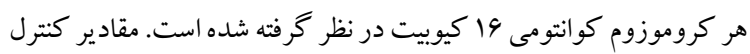

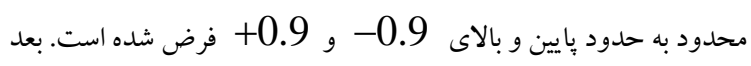
از •ا ثانيه مقادير سيخنال كنترل به بازه [0.1,0.1-0. به بازه [0.06,0.06-

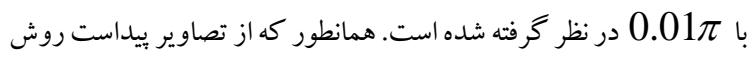

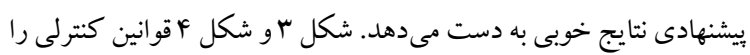
نشان مىدهند كه با استفاده از QGA به دست آمدهاند و شكل هاى هـ هو و 9 رديابى مسير تابع و خطاى رديابى به روش مذكور را نشان مىدهند.

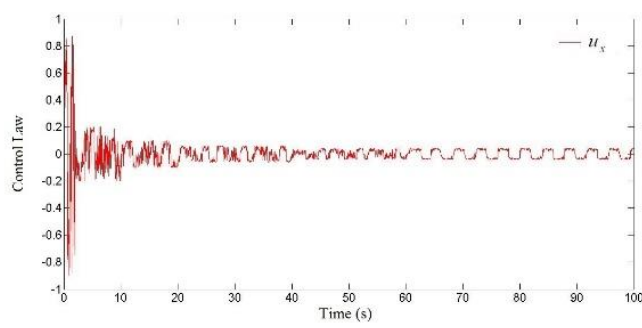
شكل كنترل

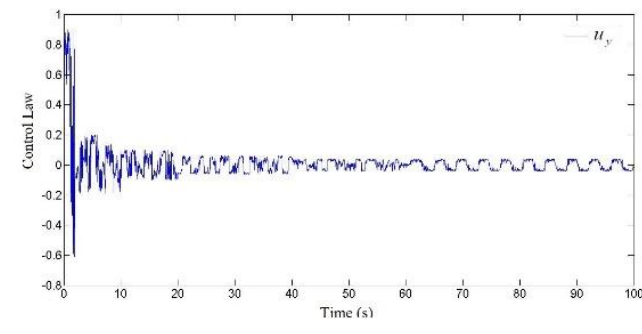
شكل F كنترل $u_{y}$

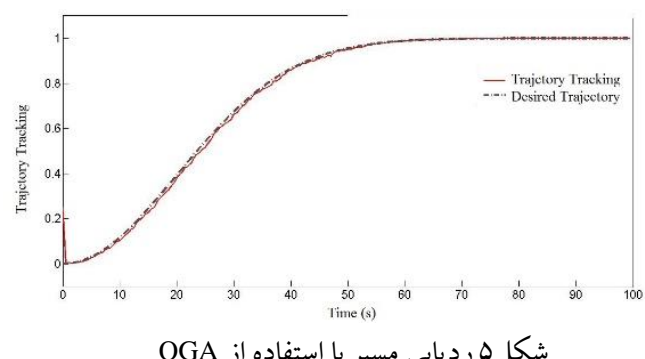

QGA شكله رديابى مسير با استفاده از هو 
[13] H. Wang, J. Liu, J. Zhi, and C. Fu, 2013, "The Improvement of Quantum Genetic Algorithm and Its Application on Function Optimization", Hindawi Publishing Corporation Mathematical Problems in Engineering.

[14] Z. Laboudi and S. Chikhi, 2011, "Comparison of Genetic Algorithm and Quantum Genetic Algorithm", The International Arab Journal of Information Technology, Vol. 9, No. 3, pp. 243-249.

[15] D. Dong, M. A. Mabrok, I. R. Petersen, B. Qi, C. Chen and H. Rabitz, 2015, "Sampling-Based Learning Control for Quantum Systems With Uncertainties", IEEE TRANSACTIONS ON CONTROL SYSTEMS TECHNOLOGY, Vol. 23, NO. 6, 2155-2166.

$$
\begin{aligned}
& \text { سيخنال كنترلى معرف هزينه كمتر كنترل است. راهبرد گفته شده را مىتوان } \\
& \text { در كاربردهاى مختلفى به كار بست. جداسازى كوانتومى و متعاقبا طبقه }
\end{aligned}
$$

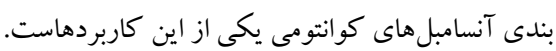

$$
\begin{aligned}
& \text { مر اجع }
\end{aligned}
$$

[1] A. Daeichian and F. Sheikholeslam, 2012, "Survey and Comparison of Quantum Systems: Modeling, Stability and Controllability", Journal of Control, Vol. 5, No. 4, pp. 2031 .

[2] C. Chen, L. C. Wang and Y. Wang, 2013, "Closed-Loop and Robust Control of Quantum Systems", The Scientific World Journal, Vol. 2013, 869285-1-869285-11.

[3] A. Narayanan and M. Moore, 1996, "Quantum-inspired genetic algorithms", in Proceedings of the IEEE International Conference on Evolutionary Computation, pp.61-66, Nagoya, Japan.

[4] J. Liu, S. Cong, and Y. Zhu, 2012, "Adaptive Trajectory Tracking of Quantum Systems", 12th International Conference on Control, Automation and Systems, Jeju Island, Korea, Oct. 17-21.

[5] W. Zhu and H. Rabitz, 2003, "Quantum control design via adaptive tracking", Journal of Chemical Physics, Vol. 119, No 7, pp. 3619-3625.

[6] Z. Sahebi and M. Yarahmadi, 2018, "Switching optimal adaptive trajectory tracking control of quantum systems", Optim Control Appl Meth. DOI: 10.1002/oca.2412.

[7] D. Dong and I. R. Petersen, 2011, "Quantum control theory and applications: A survey", IET Control Theory \& Applications, Vol. 4, No. 12, pp. 2651-2671.

[8] H. Sedghee Rostami and B. Rezaie, 2016, "Controlling state of quantum system using fuzzy controller", Modares Mechanical Engineering, Vol. 16, No. 9, pp. 124-134, (in Persian)

[9] Z. Sahebi and M. Yarahmadi, 2018, "Hybrid adaptive intelligent controller design using quantum wavelet neural networks for trajectory tracking control in finite dimensional closed quantum systems", Modares Mechanical Engineering, Vol. 18, No. 02, pp. 179-188. (in Persian)

[10] A. Arjmandzadeh and M. Yarahmadi, 2017, "Quantum genetic learning control of quantum ensembles with Hamiltonian uncertainties", Entropy, Vol. 19, No. 8, pp. 112.

[11] D. D'Alessandro, Introduction to Quantum Control and Dynamics, Taylor \& Francis Group, LLC, 2008.

[12] M. A. Nielsen and I. L. Chuang, Quantum Computation and Quantum Information, Cambridge University Press, New York, 2010. 